\title{
Peritoneal protein transport during the baseline peritoneal equilibration test is an accurate predictor of the outcome of peritoneal dialysis patients
}

\author{
Pérez-Fontán M. ${ }^{\mathrm{a}, \mathrm{b}}$ Rodríguez-Carmona A. ${ }^{\mathrm{a}}$ Barreda D. ${ }^{\mathrm{c}}$ López-Muñiz A. ${ }^{\mathrm{a}}$ Blanco- \\ Castro N. ${ }^{a}$ García-Falcón T. ${ }^{\text {a }}$ \\ ${ }^{a}$ Division of Nephrology, Complejo Hospitalario Universitario de A Coruña, and ${ }^{b}$ Department of Medicine, Health \\ Sciences Institute, University of A Coruña, A Coruña, and cDivision of Nephrology, Hospital Clínico de Granada, \\ Granada, Spain
}

\begin{abstract}
Background: Peritoneal protein excretion (PPE) is a potential marker of the outcome in peritoneal dialysis (PD) patients. Method: Observational study of a cohort of 269 patients starting PD in a single unit. Study variables: total PPE during a baseline peritoneal equilibration test (PET; PET-PPE) and 24-hour PPE. Control variables: essential baseline demographic, laboratory and adequacy markers. Main outcomes: mortality, cardiovascular events and risk of peritonitis. We applied univariate and multivariate strategies of survival analysis. Main Results: PET-PPE sustained a significant, yet limited correlation with 24-hour PPE $(\mathrm{r}=0.46, \mathrm{p}<0.0005)$. At baseline, the main study variables showed an independent correlation with peritoneal transport characteristics $\left(\mathrm{D} / \mathrm{P}_{240}\right.$, creatinine) and cardiovascular comorbidity. PET-PPE ( $p<0.0005$, model global $\chi^{2} 59.4$ ) was a more accurate predictor of overall mortality than $24-$ hour PPE $\left(\mathrm{p}=0.04, \chi^{2} 50.5\right)$. Moreover, PPE during PET, but not 24-hour PPE, was an independent predictor of the risks of cardiovascular and infectious mortality, and of peritonitis. Conclusions: Baseline PPE represents a strong independent marker of survival of PD patients. Estimation of PPE during PET is more accurate than 24-hour PPE for this purpose, sustains a definite independent association with cardiovascular and infectious mortality, and shows a significant correlation with the risk of peritonitis.
\end{abstract}

\section{Key Words}

Peritoneal equilibration test; Protein transport; Cardiovascular disease; Mortality; Peritonitis 


\section{Introduction}

Peritoneal protein excretion (PPE) is universally viewed as an adverse effect of peritoneal dialysis (PD). It plays an ill-defined role in the genesis of malnutrition of these patients [1] and may contribute, to a variable degree, to several disorders observed in PD patients, including dyslipemia, hormonal disturbances and a prothrombotic environment [2-6].

Peritoneal transport of proteins occurs essentially through large intercellular pores, and is limited by size rather than charge restriction [7-10]. Several studies have suggested that the functionality of these pores may be affected by endothelial disorders and inflammatory states [11, 12]. This raises the possibility that PPE may operate as a marker of large-pore dysfunction, indicating endothelial disease, inflammation and, eventually, cardiovascular (CV) risk for PD patients [11]. In the last few years, several studies have focused on the potential clinical significance of this hypothesis, using 24-hour PPE as a marker of this phenomenon [11, 13-15].

The peritoneal equilibration test (PET) is the standard procedure for the categorization of peritoneal transport characteristics in clinical practice [16]. As such, it is focused on the behavior of small solutes, including creatinine and glucose. However, it can also be used to categorize the peritoneal transport of different proteins [7, 16-18]. We have recently shown that the PET permits a standardized and reproducible assessment of the peritoneal transport of total proteins, seemingly providing a more focused view of this phenomenon than analysis of 24-hour PPE [19]. We present the results of a study aimed to compare the accuracy of both approaches to categorize the overall risk of a wide cohort of patients starting chronic PD therapy in a single center.

\section{Population and Method}

\section{General Design}

We analyzed a historic cohort of patients starting PD in a single unit (University Hospital of A Coruña, Spain) between January 2000 and December 2008. Follow-up was finished by May 31, 2009. The main objective of the study was to analyze the ability of PPE estimated from baseline 24-hour or PET dialysate collections to predict the outcome of these patients. We applied a multivariate strategy of analysis to control for factors known to have a significant impact on general prognosis during PD therapy. The study protocol fulfilled the ethical requirements for noninterventional retrospective cohort studies demanded by our institution.

\section{Population}

For analysis, we included all patients starting PD during the above-mentioned period who fulfilled two conditions: minimal follow-up of two months without peritonitis, and baseline $(\leq 2$ months since initiation of PD) estimation of PPE in both 24-hour and PET dialysate collections. 286 patients were scrutinized, but 17 patients were excluded from analysis due to death or discontinuing PD after less than 2 months of follow-up $(n=10)$, baseline 24-hour PPE and/or PET-PPE not available $(n=6)$ or inadequate clinical records $(n=1)$. Table 1 depicts the main clinical characteristics of the final study population at the inception of PD therapy. All patients used lactate-based solutions for routine PD, while 56 patients on CAPD (34.4\%) and 71 on automated PD (67.0\%) had icodextrin for the long dwell at the time of the baseline sample collection. 


\begin{tabular}{|c|c|}
\hline Age, years & $57.3 \pm 16.1(8,87)$ \\
\hline Gender, males/females (\%) & $167 / 102(62.1 / 37.9)$ \\
\hline \multicolumn{2}{|l|}{ Underlying renal disease } \\
\hline Chronic glomerulonephritis & $33(12.3)$ \\
\hline Vascular & $20(7.4)$ \\
\hline Interstitial & $23(8.6)$ \\
\hline Cystic & $23(8.6)$ \\
\hline Diabetic nephropathy & $74(27.5)$ \\
\hline Systemic & $12(4.4)$ \\
\hline Other unknown & $84(31.3)$ \\
\hline PD modality, CAPD/automated PD (\%) & $163 / 106(60.6 / 39.4)$ \\
\hline Diabetes $(\%)$ & $98(36.4)$ \\
\hline \multicolumn{2}{|l|}{ Baseline cardiovascular comorbidities } \\
\hline Ischemic heart disease & $63(23.1)$ \\
\hline Stroke & $30(11.1)$ \\
\hline Peripheral arterial disease & $32(11.9)$ \\
\hline Major arrhythmia & $28(10.4)$ \\
\hline Heart failure & $55(20.4)$ \\
\hline Other heart diseases & $35(13.1)$ \\
\hline Patients with at least one cardiovascular comorbidity & $130(48.3)$ \\
\hline \multicolumn{2}{|l|}{ Baseline noncardiovascular comorbidities } \\
\hline Pulmonary disease & $21(7.8)$ \\
\hline Liver disease & $23(8.6)$ \\
\hline Neoplasia & $21(7.8)$ \\
\hline Major depression & $23(8.6)$ \\
\hline Charlson's comorbidity score & $3.91 \pm 1.89(2,9)$ \\
\hline Cardiovascular comorbidity score & $1.42 \pm 1.83(0,7)$ \\
\hline Systolic blood pressure, $\mathrm{mm} \mathrm{Hg}$ & $137.2 \pm 17.8(80,195)$ \\
\hline Diastolic blood pressure, $\mathrm{mm} \mathrm{Hg}$ & $79.1 \pm 10.9(45,105)$ \\
\hline Number of antihypertensive drugs & $1.45 \pm 0.96(0,5)$ \\
\hline Malnutrition, any degree (Subjective Global Assessment) & $34(12.6)$ \\
\hline BMI & $25.9 \pm 4.6(15.4,43.5)$ \\
\hline
\end{tabular}

Numerical variables presented as mean values \pm SD (range).

Categorical variables presented as $\mathrm{n}(\%)$.

\section{Study Variables}

We recorded the baseline clinical characteristics of patients at baseline (table 1). The modality of PD was computed according to the status of the patient at the end of the second month of follow-up. Baseline comorbidity was categorized in two different ways. The Charlson's comorbidity score was used as a control variable for general outcomes, while for CV outcomes, we only applied CV comorbidity as a control variable. For this purpose, we created a CV comorbidity score, which was gained from the arithmetic addition of the accumulated $\mathrm{CV}$ comorbities with a correction factor for severity $(0=$ absent; 1 $=$ uncomplicated, i.e. medical management and no patent sequelae; $2=$ complicated, i.e. invasive measures required or significant sequelae after event). Age was managed as an independent control variable, aside from Charlson's score. Blood pressure was estimated from mean values recorded during the second month of home PD therapy. Malnutrition was diagnosed by standard Subjective Global Assessment, performed routinely at the start of PD therapy in our unit. It was managed as a binary variable, due to the extremely low baseline prevalence of severe malnutrition in the cohort. Body mass index (BMI) was estimated as weight $(\mathrm{kg}) / \mathrm{height}^{2}\left(\mathrm{~m}^{2}\right)$.

Table 2 presents the baseline control laboratory and adequacy variables. Glomerular filtration rate (GFR) was computed as the mean of urea and creatinine clearances. Daily ultrafiltration was obtained from the clinical records of the patients, and computed as the mean value during the second month of therapy. A standard PET with 2 liters of $2.27 \%$ glucose-based, lactate-buffered dialysate was performed in all patients during their second month on PD. We used D/P of creatinine at 240 ' (D/P 240 , creatinine) as the surrogate of peritoneal transport characteristics. All the study variables presented in tables 1 and 2 were available for analysis in $>95 \%$ of the patients. 
Table 2. Study population: baseline laboratory and adequacy data

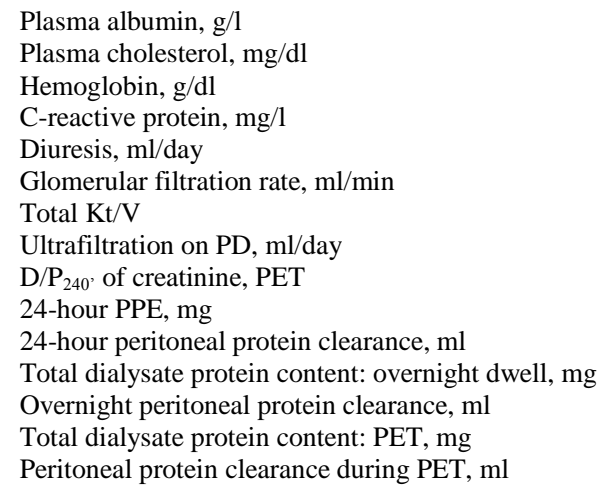

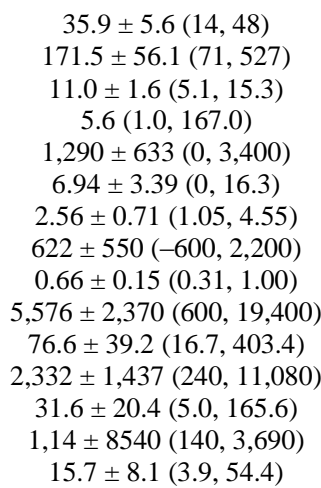

Numerical variables presented as mean values \pm SD (range), except C-reactive protein, presented as the median (range).

The main study variables were scrutinized for total protein excretion (24-hour PPE and PET-PPE) and total protein clearance (PCl; 24-hour PCl and PET-PCl). Twenty-four-hour PPE was estimated from a full 24-hour dialysate collection for adequacy during the second month on PD, with a median time lapse versus PET of 7 days (range 0,26). PET-PPE was computed as the total amount of protein in dialysate at the end of the baseline PET. Peritoneal protein clearance was estimated from the formulas PET$\mathrm{PPE} /($ serum albumin/0.4783) (PET-PCl) and 24-hour PPE/(serum albumin/ 0.4783) (24-hour PCl) [20].

The main outcome variables scrutinized included mortality (overall, CV and infectious), CV morbidity (estimated from CV events demanding hospital admission) and PD-related peritonitis. In patients with several coexistent causes of death, mortality was assigned to that quoted as the main one at the time of demise.

\section{Laboratory Methods}

Blood levels of hemoglobin, glucose, urea, creatinine, albumin and cholesterol were quantified with a standard autoanalyzer (Advia 2400; Bayer®). Dialysate levels of glucose and creatinine, and urine levels of urea and creatinine, were estimated with adapted software from the same autoanalyzer. We corrected dialysate creatinine levels for simultaneous glucose levels. Plasma C-reactive protein was estimated using an immunoturbidimetric assay (Roche Diagnostics, Mannheim, Germany).

A modified colorimetric assay (pirogalol red) was used for estimation of urine and dialysate total protein content. We have shown in a previous study [19] that this method is accurate and not affected by high concentrations of glucose in dialysate.

\section{Strategy of Analysis}

Data analysis was carried out following two main steps. First, we attempted to disclose correlations between the main study variables (PET-PPE/PCl and 24-hour PPE/PCl) on one side, and the clinical and laboratory markers scrutinized on the other. Secondly, we searched for the specific prognostic significance of the main study variables. For the univariate approach, we categorized the latter binarily (above/below the corresponding median values). Then we applied a multivariate strategy to obtain an adjusted effect for each study variable on each selected outcome. To avoid colinearity, serum albumin was excluded from PCl models. Comparisons between the efficiency of PET-PPE/PCl and 24- hour $\mathrm{PPE} / \mathrm{PCl}$ as prognostic markers were based on the consistency of each variable to predict outcomes and the overall quality of the final models (global $\chi^{2}$ value). 
Statistics

Numerical variables are presented as the mean \pm SD or median values (range), as appropriate. Univariate comparisons between variables were produced according to Student's t test, ANOVA, MannWhitney and Wilcoxon tests (numerical), and $\chi^{2}$ distribution (categorical). We calculated correlations between numerical variables from Spearman's correlation coefficient. Multivariate baseline correlates of PPE were assessed by stepwise multiple regression analysis. Univariate survival analysis was based on Kaplan-Meier's method (comparisons log-rank test). Multivariate survival analysis was based on the Cox proportional hazards model. Cases were censored at recovery of renal function, switch to hemodialysis, loss to follow-up or renal transplant. We used SPSS 17.0 for data processing.

\section{Results}

\section{Overview}

Tables 1 and 2 depict the main baseline clinical, laboratory and adequacy variables scrutinized. Table 3 details the clinical outcomes of the whole cohort. Thirty-two percent of the patients suffered at least one $\mathrm{CV}$ event, and $36 \%$ of the patients died during follow-up. CV disease was the main cause of death, but infection, failure to thrive and miscellaneous causes also made up a significant proportion of deaths.

Table 3. Main clinical outcomes

\begin{tabular}{|c|c|}
\hline Follow-up, months & $29.0 \pm 17.5(2,96)$ \\
\hline $\begin{array}{l}\text { Cardiovascular events during follow-up } \\
\text { Ischemic heart disease ( } 29 \text { patients) } \\
\text { Stroke ( } 11 \text { patients) } \\
\text { Peripheral vasculopathy ( } 32 \text { patients) } \\
\text { Heart failure ( } 24 \text { patients) } \\
\text { Other cardiovascular events ( } 14 \text { patients) } \\
\text { Events - patients with at least one event ( } 86 \text { patients) }\end{array}$ & $\begin{array}{c}39(10.8) \\
13(4.1) \\
45(11.9) \\
42(8.9) \\
16(5.2) \\
155(32.0)\end{array}$ \\
\hline Peritonitis (n/patient) & $1.11 \pm 1.52(0,8)$ \\
\hline $\begin{array}{l}\text { Drop-out to hemodialysis } \\
\text { Inadequacy/ultrafiltration failure } \\
\text { Peritonitis } \\
\text { Other }\end{array}$ & $\begin{array}{c}32(12.9) \\
8(3.0) \\
10(3.7) \\
14(5.2)\end{array}$ \\
\hline $\begin{array}{l}\text { Deaths } \\
\text { Cardiovascular } \\
\text { Myocardial infarction } \\
\text { Heart failure } \\
\text { Sudden death } \\
\text { Mesenteric thrombosis } \\
\text { Peripheral vasculopathy } \\
\text { Stroke } \\
\text { Other }\end{array}$ & $\begin{array}{c}97(36.0) \\
43(16.0) \\
10 \\
3 \\
12 \\
2 \\
9 \\
3 \\
4\end{array}$ \\
\hline $\begin{array}{l}\text { Infection } \\
\quad \text { Peritonitis } \\
\quad \text { Other infections } \\
\text { Failure to thrive - withdrawal from dialysis } \\
\text { Neoplasia }\end{array}$ & $\begin{array}{c}21(7.8) \\
9 \\
12 \\
13(4.8) \\
6(2.2)\end{array}$ \\
\hline Other & $14(5.2)$ \\
\hline $\begin{array}{l}\text { Other } \\
\text { Renal transplantation } \\
\text { Active on PD at end of follow-up } \\
\text { Lost to follow-up } \\
\text { Recovery of renal function - PD suspended }\end{array}$ & $\begin{array}{l}140(52.0) \\
71(26.4) \\
60(22.3) \\
6(2.2) \\
3(1.1)\end{array}$ \\
\hline
\end{tabular}

Numerical variables presented as mean values \pm SD (range). Categorical variables presented as $\mathrm{n}(\%)$ 
Analysis of both total PPE (overall $\mathrm{r}$ value 0.46, $\mathrm{p}<0.0005$; fig. 1) and $\mathrm{PCl}(\mathrm{r}=0.50, \mathrm{p}<0.0005$ ) showed a significant correlation between PET and the 24-hour sample collection. However, the correlation was limited, indicating that both methods of estimation were not interchangeable. For instance, by setting an arbitrary limit at the mean $+1 \mathrm{SD}, 58$ patients were quoted as high protein transporters by either PET-PPE or 24-hour PPE, and only $12(20.7 \%)$ were categorized as such by both methods $($ Kappa $=0.24)$. Interestingly, the correlation between both estimations was lower for automated PD than for CAPD patients (fig. 1).

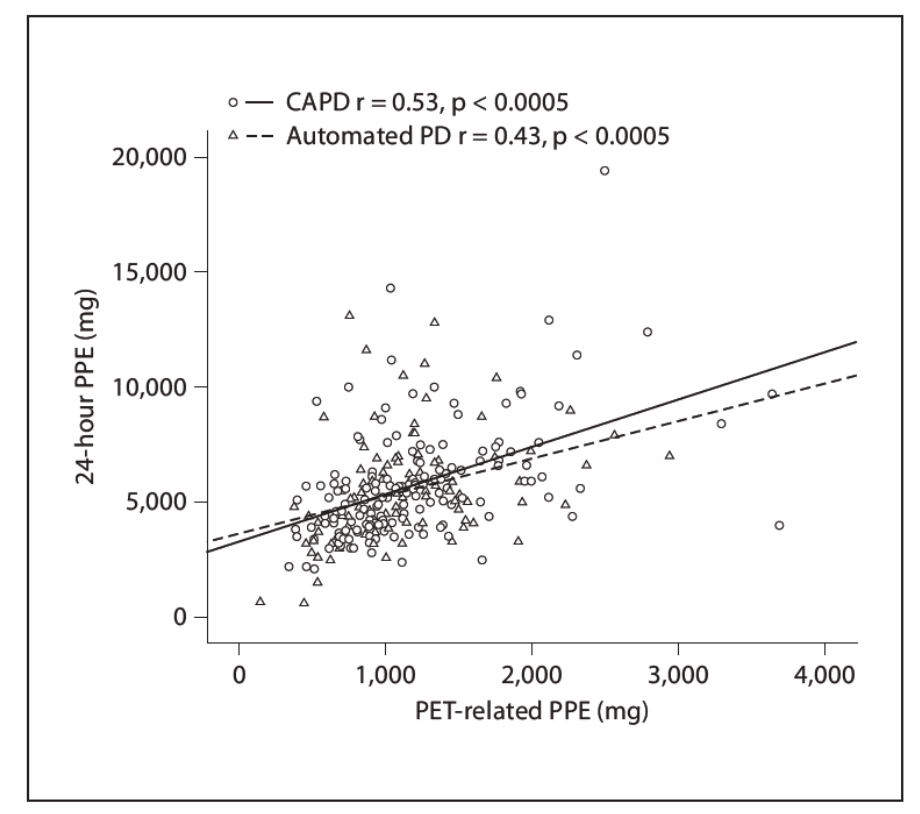

Fig. 1. Correlation between PPE assessed from baseline PETs and 24-hour dialysate collections.

\section{Correlates of PPE}

Table 4 shows the most important univariate correlates of the main study variables. PET-PCl and 24hour PCl displayed overall similar coefficients compared to PET-PPE and 24-hour-PPE, respectively (not represented). There were clear trends to an association between both variables on one side and $\mathrm{D} / \mathrm{P}_{240}$, of creatinine and markers of $\mathrm{CV}$ disease (diabetes, comorbidity scores) on the other. Multiple regression analysis disclosed $\mathrm{D} / \mathrm{P}_{240}$, of creatinine $(\mathrm{B}=9.53 ; 95 \% \mathrm{CI} 5.36,13.69 ; \mathrm{p}<0.0005)$, presence of diabetes mellitus ( $\mathrm{B}=1.97 ; 95 \% \mathrm{CI} 0.54,3.41 ; \mathrm{p}=0.007)$, the $\mathrm{CV}$ comorbidity score $(\mathrm{B}=0.32 ; 95 \% \mathrm{CI} 0.03$, $0.68 ; \mathrm{p}=0.043)$ and systolic blood pressure $(\mathrm{B}=0.04 ; 95 \% \mathrm{CI}-0.001,0.07 ; \mathrm{p}=0.057)$ as independent predictors of PET-PPE (model $\left.\mathrm{r}^{2} 0.21\right)$. On the other side, only $\mathrm{D} / \mathrm{P}{ }_{240}$, of creatinine $(\mathrm{B}=22.74 ; 95 \% \mathrm{CI}$ $4.36,42.11 ; \mathrm{p}=0.002)$ and the $\mathrm{CV}$ comorbidity score $(\mathrm{B}=1.80 ; 95 \% \mathrm{CI} 0.16,3.43 ; \mathrm{p}=0.031)$ showed an independent association with 24-hour PPE (model $r^{2} 0.07$ ). 
Table 4. Main univariate correlates of PPE

\begin{tabular}{lll}
\hline & PPE during PET & 24-hour PPE \\
\hline Age & $0.07(0.26)$ & $0.09(0.15)$ \\
Diabetes & $0.17(0.01)$ & $0.11(0.10)$ \\
Gender & $-0.006(0.92)$ & $-0.096(0.12)$ \\
Mode of PD & $-0.03(0.62)$ & $-0.04(0.48)$ \\
Charlson's score & $0.22(0.0005)$ & $0.16(0.011)$ \\
CV comorbidity score & $0.19(0.002)$ & $0.17(0.006)$ \\
Systolic blood pressure & $0.11(0.11)$ & $0.09(0.13)$ \\
Diastolic blood pressure & $-0.06(0.30)$ & $-0.01(0.92)$ \\
BMI & $0.05(0.39)$ & $0.10(0.11)$ \\
Malnutrition (SGA) & $0.07(0.25)$ & $0.03(0.63)$ \\
Plasma albumin & $-0.003(0.97)$ & $-0.038(0.54)$ \\
Cholesterol & $-0.10(0.12)$ & $-0.13(0.042)$ \\
Hemoglobin & $-0.13(0.035)$ & $-0.06(0.33)$ \\
C-reactive protein & $0.04(0.55)$ & $0.16(0.008)$ \\
Glomerular filtration rate & $-0.01(0.86)$ & $0.02(0.80)$ \\
Kt/V & $-0.07(0.25)$ & $0.02(0.72)$ \\
D/P 240 $_{\text {, creatinine }}$ & $0.31(0.0005)$ & $0.21(0.0005)$ \\
& & \\
\hline
\end{tabular}

Figures denote Spearman's correlation coefficients ( $\mathrm{p}$ value).

\section{Association between PPE and Clinical Outcomes:Univariate Analysis}

Figure 2 shows that PET-PPE is a significant univariate predictor of overall survival of PD patients (fig. 2a). Twenty- four-hour PPE (fig. 2b), however, did not show such a capacity of discrimination. Interestingly, the predictive capacity of PET-PPE seemed to include both CV (fig. 3a) and infectious (fig. 4a) mortality. Twenty-four-hour PPE was unable to predict these outcomes (fig. 3b, 4 b).

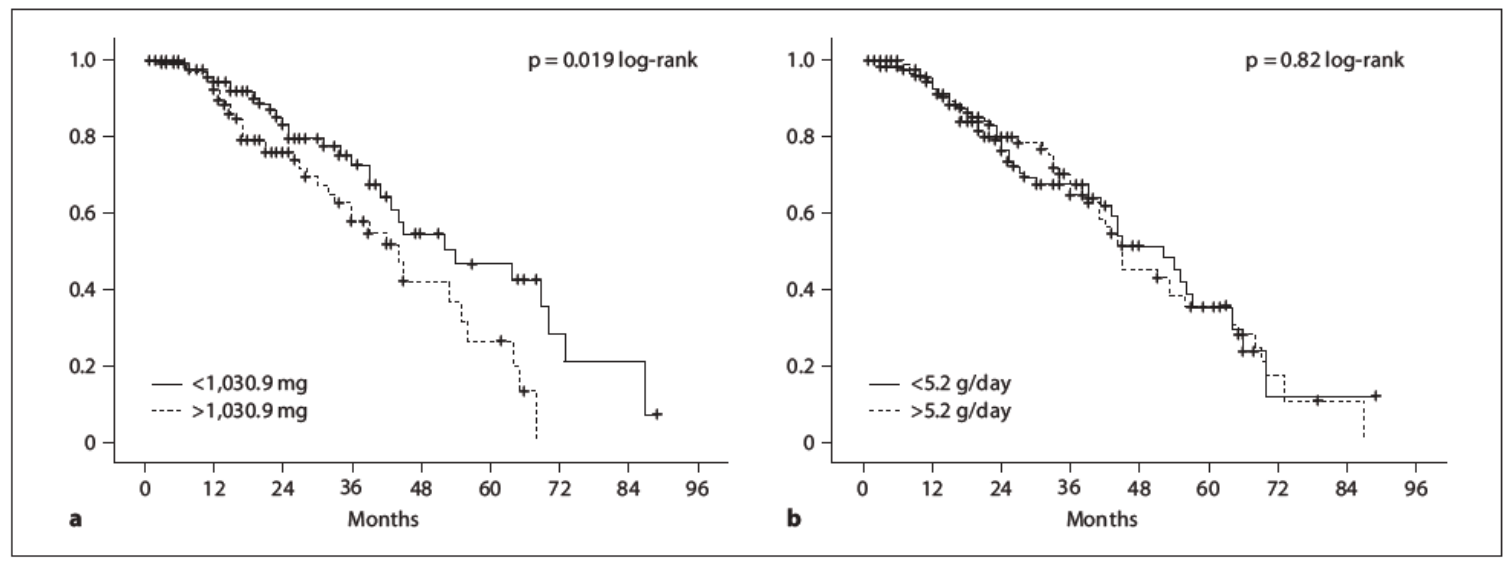

Fig. 2. Kaplan-Meier plot of overall survival risk according to PPE assessed from baseline PET (a) and 24-hour dialysate collection (b). $1,030.9 \mathrm{mg}(\mathbf{a})$ and $5.2 \mathrm{~g}(\mathbf{b})$ represent median values. 


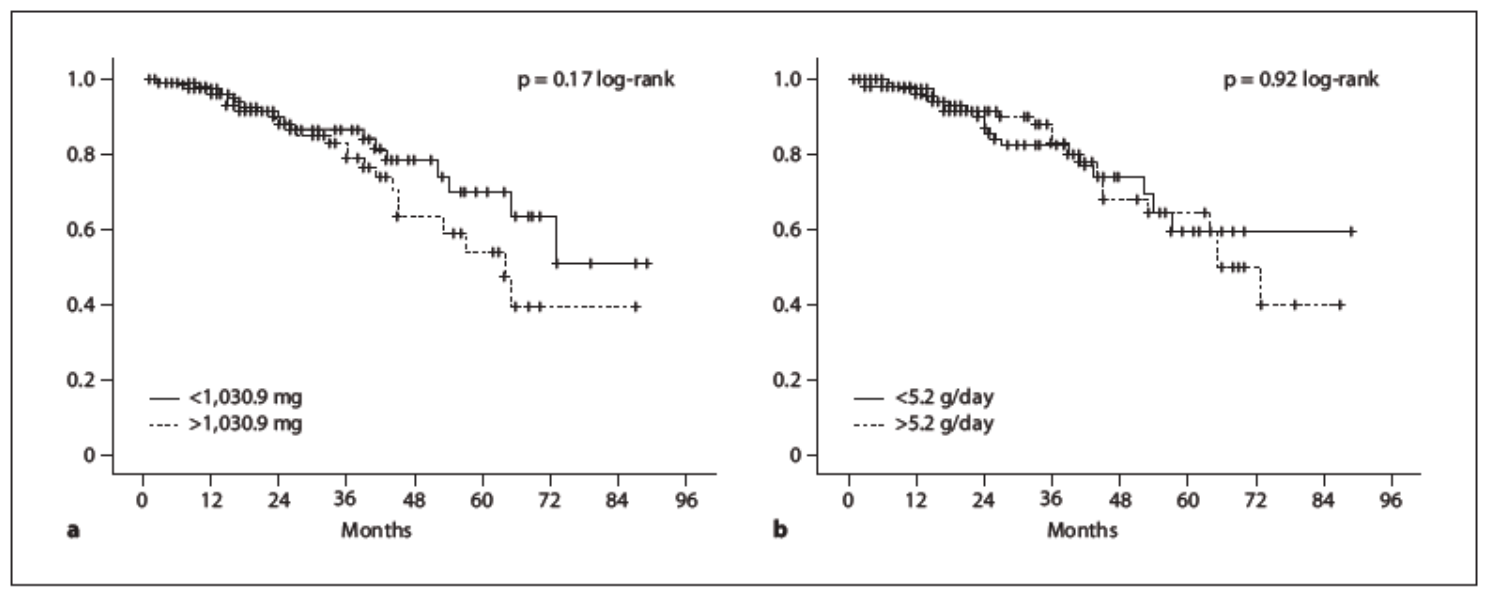

Fig. 3. Kaplan-Meier plot of CV mortality risk according to PPE assessed from baseline PET ( a ) and 24-hour dialysate collection ( b ). $1,030.9 \mathrm{mg}$ ( a ) and $5.2 \mathrm{~g}$ ( $\mathbf{b}$ ) represent median values.

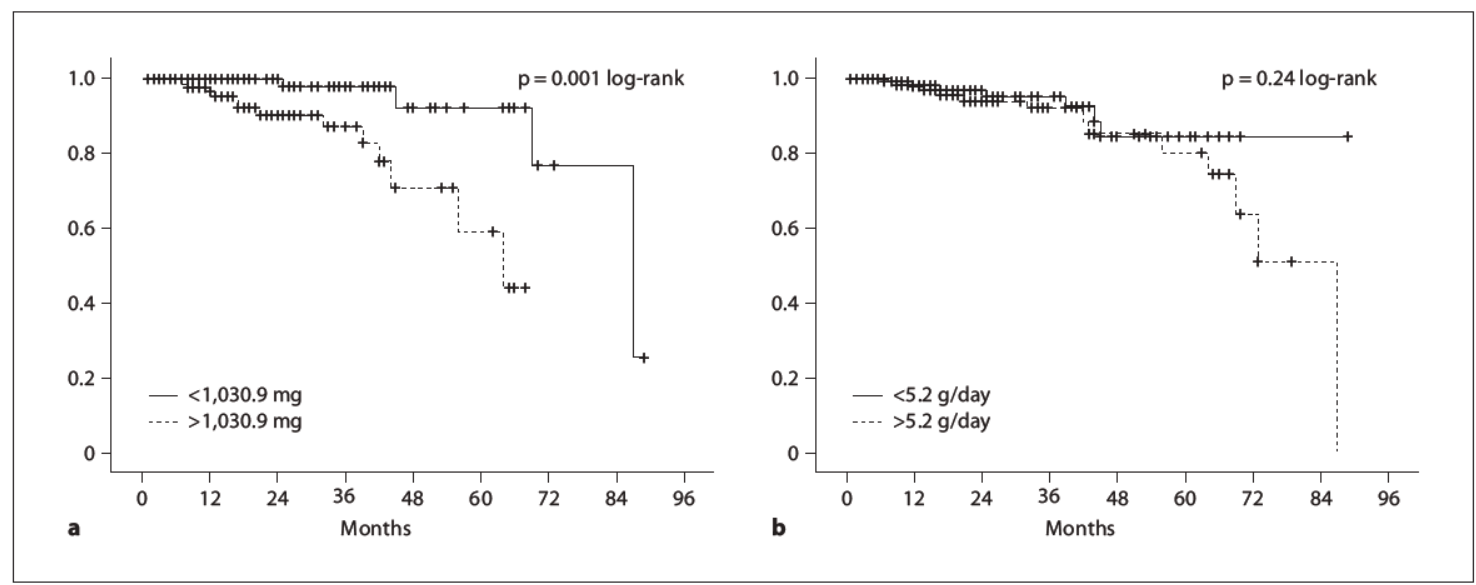

Fig. 4. Kaplan-Meier plot of infectious mortality risk according to PPE assessed from baseline PET (a) and 24-hour dialysate collection (b). $1,030.9 \mathrm{mg}(\mathbf{a})$ and $5.2 \mathrm{~g}(\mathbf{b})$ represent median values.

We observed no univariate correlation between PETPPE or 24-hour PPE on one side, and survival to the first $\mathrm{CV}$ event on the other. The number of $\mathrm{CV}$ events during follow-up did not show any univariate association with the main study variables.

We observed a nonsignificant trend to a lower survival to the first episode of peritonitis among patients above the median value of PET-PPE (fig. 5a), without differences related to 24-hour PPE (fig. $5 \mathrm{~b})$. The incidence of peritonitis was similar according to PET-PPE (0.50 vs. 0.56 episodes/patient/year below/above median, $\mathrm{p}=0.54$ ) and 24-hour PPE (0.58 vs. 0.47 episodes/patient/year, respectively, $\mathrm{p}=$ $0.14)$.

Use of PET-PCl or 24-hour PCl yielded very similar results to PET-PPE and 24-hour PPE, respectively, but is not represented. 

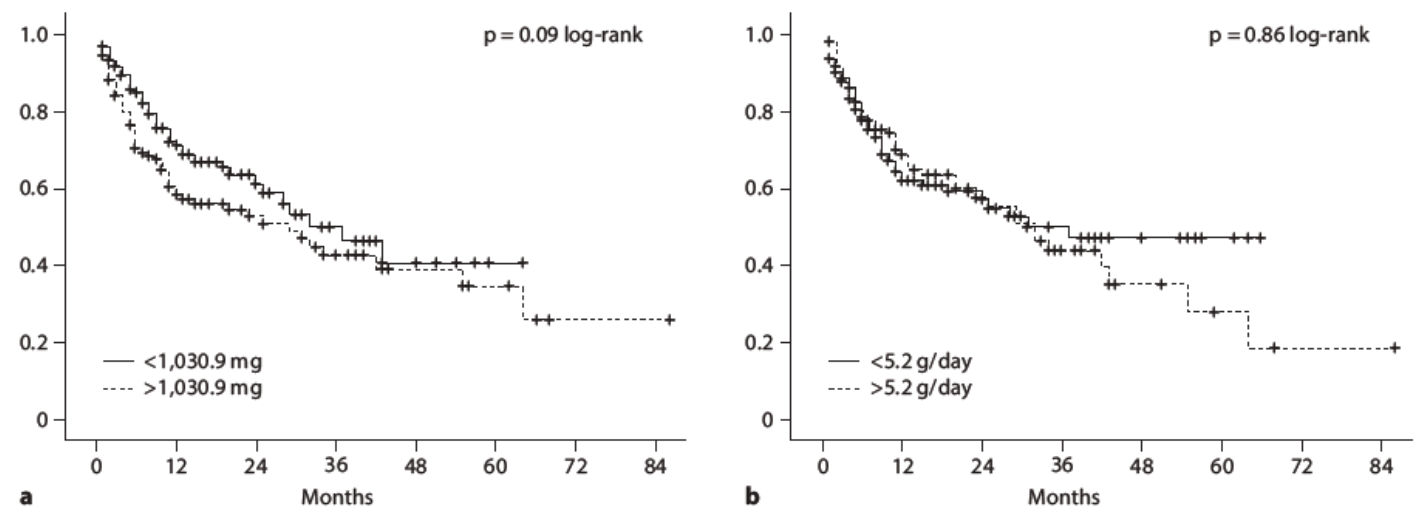

Fig. 5. Kaplan-Meier plot of survival to the first episode of peritonitis according to PPE assessed from baseline PET (a) and 24-hour dialysate collection (b). $1030.9 \mathrm{mg}$ (a) and $5.2 \mathrm{~g}(\mathbf{b})$ represent median values.

\section{Association between PPE and Clinical Outcomes: Multivariate Analysis}

Tables 5 and 6 show the main results of multivariate analysis. Overall peritoneal transport characteristics (as estimated by $\mathrm{D} / \mathrm{P}_{240}$, creatinine) did not show a correlation with any of the outcome variables scrutinized. On the contrary, both PET-PPE/PCl and 24-hour PPE/PCl behaved as independent predictors of overall survival, after controlling for other significant covariates (table 5). PET-PPE/PCl was clearly a more powerful predictor of outcome than 24-hour $\mathrm{PPE} / \mathrm{PCl}$, permitting a more accurate global model. We detected significant interaction terms between C-reactive protein and Charlson's score in both the PET-PPE/PCl and the 24-hour PPE/PCl models, but they did not significantly affect the coefficients for the main study variables. We also found a moderate interaction between age and 24-hour $\mathrm{PPE} / \mathrm{PCl}(\mathrm{p}=0.043 / 0.049)$, suggesting that the latter variable was more predictive of an adverse outcome in younger patients. We ignored this interaction in the presentation of the models for better clarity (table $5)$.

Table 5. Correlation between overall mortality and different markers of PPE: multivariate analysis

\begin{tabular}{|c|c|c|c|c|c|}
\hline Covariables & HR & $95 \% \mathrm{CI}$ & $\mathrm{p}$ & Wald & Model $\chi^{2}$ \\
\hline PPE during PET, $100 \mathrm{mg}$ & 1.07 & $1.03,1.12$ & 0.0005 & 12.02 & 59.4 \\
\hline Charlson's score, points & 1.13 & $1.01,1.27$ & 0.039 & 5.33 & \\
\hline Plasma albumin, g/l & 0.93 & $0.89,0.97$ & 0.0005 & 12.56 & \\
\hline C-reactive protein, $\mathrm{mg} / \mathrm{l}$ & 1.09 & $1.00,1.21$ & 0.05 & 3.83 & \\
\hline Age, years & 1.04 & $1.02,1.07$ & 0.0005 & 15.46 & \\
\hline Charlson's score, points & 1.17 & $1.04,1.31$ & 0.039 & 5.33 & \\
\hline C-reactive protein, $\mathrm{mg} / \mathrm{l}$ & 1.09 & $1.00,1.21$ & 0.05 & 3.83 & \\
\hline 24-hour PPE, $500 \mathrm{mg}$ & 1.04 & $1.00,1.08$ & 0.04 & 4.04 & 50.5 \\
\hline Age, years & 1.07 & $1.02,1.06$ & 0.0005 & 14.19 & \\
\hline Charlson's score, points & 1.15 & $1.03,1.28$ & 0.019 & 5.55 & \\
\hline Charlson's score, points & 1.20 & $1.08,1.34$ & 0.001 & 10.77 & \\
\hline Glomerular filtration rate, $\mathrm{ml} / \mathrm{min}$ & 0.95 & $0.89,1.00$ & 0.055 & 3.75 & \\
\hline
\end{tabular}

Cox's proportional hazards models. Best model. 
Table 6. Other outcome correlates of peritoneal protein excretion: multivariate analysis

\begin{tabular}{|c|c|c|c|c|c|c|}
\hline Dependent variables & HR & $95 \% \mathrm{CI}$ & $\mathrm{p}$ & Wald & Model $\chi^{2}$ & $\begin{array}{l}\text { Covariates in } \\
\text { best model }\end{array}$ \\
\hline \multicolumn{7}{|l|}{ Cardiovascular mortality } \\
\hline PET-PCl, $10 \mathrm{ml}$ & 1.76 & $1.22,2.55$ & 0.002 & 9.15 & 32.0 & diabetes \\
\hline 24-hour PPE, 500 mg & 1.01 & $0.95,1.09$ & 0.69 & 0.32 & 31.2 & CV score \\
\hline 24-hour PCl, $10 \mathrm{ml}$ & 1.04 & $0.94,1.12$ & 0.54 & 0.38 & 22.5 & albumin \\
\hline PPE during PET, $100 \mathrm{mg}$ & 1.02 & $0.96,1.06$ & 0.71 & 0.24 & 36.7 & age \\
\hline PET-PCl, $10 \mathrm{ml}$ & 1.31 & $0.91,1.88$ & 0.14 & 21.7 & 30.3 & diabetes \\
\hline 24-hour PPE, 500 mg & 1.00 & $0.95,1.05$ & 0.85 & 0.44 & 31.3 & CV score \\
\hline 24-hour PCl, $10 \mathrm{ml}$ & 0.97 & $0.89,1.05$ & 0.04 & 0.60 & 30.4 & albumin \\
\hline \multicolumn{7}{|l|}{ Infectious mortality } \\
\hline PPE during PET, $100 \mathrm{mg}$ & 1.12 & $1.04,1.21$ & 0.006 & 6.32 & 21.7 & age \\
\hline \multicolumn{7}{|l|}{ First peritonitis } \\
\hline PPE during PET, $100 \mathrm{mg}$ & 1.04 & $1.00,1.07$ & 0.037 & 4.35 & 19.4 & age \\
\hline PET-PCl, $10 \mathrm{ml}$ & 1.37 & $1.12,1.68$ & 0.02 & 10.63 & 19.1 & mode of PD \\
\hline 24-hour PPE, 500 mg & 1.00 & $0.97,1.04$ & 0.86 & 0.04 & 15.0 & CRP \\
\hline 24-hour PCl, $10 \mathrm{ml}$ & 1.03 & $0.99,1.07$ & 0.17 & 2.13 & 15.1 & \\
\hline
\end{tabular}

Cox's proportional hazards models. $\mathrm{CRP}=\mathrm{C}$-reactive protein

Both $\mathrm{CV}$ and infectious mortality were independently and individually predicted by PET-PPE/PCl, but not by 24-hour PPE/PCl (table 6). The same applied for survival to the first episode of peritonitis. No interaction terms were detected for any of these models. Finally, neither PET-PPE/PCl or 24-hour $\mathrm{PPE} / \mathrm{PCl}$ were independently predictive of survival to the first $\mathrm{CV}$ event (table 6).

\section{Discussion}

Our study confirms previous reports $[11,13-15]$ indicating that PPE is an independent predictor of survival in patients starting PD therapy. There are several potential explanations for this correlation. First, protein depletion may impact negatively on the nutritional state of these patients [1]. For years, this was the main concern associated with this side effect of PD. The apparent inverse correlation between PPE and serum albumin levels seemed to support this notion. Current knowledge indicates that this association is actually more complex, implicating other factors such as peritoneal membrane transport characteristics, endothelial dysfunction, inflammation, volume overload, etc. [11, 21-29]. The specific nutritional impact of the peritoneal protein leak in PD patients is currently unclear. On the other hand, depletion of specific proteins may contribute to a series of disorders observed in PD patients, including dyslipidemia, hormonal disturbances and a prothrombotic environment [2-6]. It is also conceivable that the immune competence of these patients may be compromised by the continuous leak of immunoactive proteins. More recently, several studies have provided a different insight into the question, by contemplating PPE as a marker for peritoneal large pore dysfunction [11, 12,30]. Under this perspective, PPE could be a marker of systemic endothelial dysfunction and inflammation akin, to a certain point, to proteinuria, rather than a pathogenic disorder itself. The observed association between PPE and CV disease at the start of dialysis $[11,14,15$, present study] supports this point of view. Overall, hypotheses contemplating PPE either as a marker of vascular disease or as a pathogenic disorder are not mutually exclusive, and may help explain the association between PPE and the outcome of PD patients.

According to our data, PPE during the baseline PET is a more accurate predictor of outcome than PPE calculated from 24-hour dialysate collections. The PET permits a standard, reproducible estimation of peritoneal protein transport, as opposed to assessment from 24- hour dialysate collections, which may be biased by other factors unrelated to the prognosis of PD patients. For instance, inconsistencies in the collection and management of samples are more likely during 24-hour collections. Patients treated with automated PD may be particularly prone to incorrect sampling, which may help to explain the poorer correlation between the scrutinized tests observed in this subgroup (fig. 1). Otherwise, a previous study from our group [19] showed that the results of the 2.27 and 3.86\% PET are comparable in relation to PPE, provided total $\mathrm{PPE}$ or $\mathrm{PCl}$, rather than dialysate protein concentrations, are used for analysis. We also 
demonstrated that the pirogalol red method for estimating dialysate protein levels is not affected by dialysate glucose concentration or storage [19], although this needs to be tested for the other individual methods. Biases induced by storage of spent dialysate should be more of a concern during 24-hour, rather than in PET, dialysate collections. On the other hand, the PD schedule may influence 24-hour PPE, although there is some controversy about the real impact of this factor, fed by a paucity of quality studies assessing this question [19, 21, 22, 31, 32]. Overall, PET-PPE may be a more specific marker of peritoneal large-pore dysfunction than 24-hour PPE. The latter should be less disadvantageous at the time of establishing correlations with PPE-induced malnutrition and metabolic disorders because it estimates the real amount of PPE.

PET-PPE/PCl was able to predict different outcomes of our patients. The background hypothesis could suggest a primary CV impact on PPE, but the correlation with infectious mortality and peritonitis was clear (table 6). A previous study [11] reported a significant infectious mortality among PD patients with higher large-pore areas. This finding should not be unexpected because, as a whole, a high PPE marks a poor general condition of PD patients. We have shown in a previous study [33] that general prognostic factors, such as older age, malnutrition, inflammation or a low glomerular filtration rate, portend a high risk of peritonitis-related mortality. The design of the present study does not permit the assessment of the specific roles played by PPE induced malnutrition or peritoneal depletion of immunoactive proteins on infectious morbidity and mortality of these patients.

PET-PPE and PET-PCl were roughly equivalent at the time of predicting the outcome of PD patients, which should not represent a surprise given the expectedly tight correlation between both variables $(\mathrm{r}=$ 0.94). We advocate PET-PPE over PET-PCl, both for theoretical and practical reasons. There are some limitations to the use of the a priori attractive concept of $\mathrm{PCl}$ in this setting. The term 'total protein' includes an array of substances with different peritoneal transport rates. Plotting dialysate versus serum total protein is, thus, conceptually misleading. An estimation using serum albumin as the reference value [15, present study] has been proposed by Haraldsson [20], and is based on the idea that albumin is the main protein implicated in peritoneal transport. However, the applied correction factor is generic, which does not add precision to the estimation of PPE in individual patients. PCl of albumin may be a good alternative [11], but routine determination of dialysate albumin is generally less convenient than that of total protein. Moreover, the prognostic significance of the $\mathrm{PCl}$ of albumin and total protein may not be the same, and the former needs specific assessment. In our study, the use of PPE and albumin separately, rather than as a composite variable $(\mathrm{PCl})$, permitted better mathematical models in the majority of cases (tables 5, 6). Overall, PET-PPE - in our opinion - is simple, easy to interpret and slightly more predictive than PET-PCl.

The main strengths of this study are the good quality of the data base used for analysis and the consistency of the main results. The limitations include its retrospective nature and a limited statistical potency. The latter may underlie the relative inconsistency of multivariate models for some secondary outcomes (e.g. CV events), and limits our capacity to disclose some important questions. For instance, our data do not permit an analysis of the potential links between PPE, malnutrition and mortality because the prevalence of overt malnutrition was low (table 1).

In summary, our study shows a definite correlation between baseline PPE during PD on one side and peritoneal transport characteristics and CV comorbidity on the other, as PPE represents an independent predictor of outcome of PD patients. Quantification of total dialysate protein content at the end of a standard PET is a reproducible and accurate estimator of PPE, and is seemingly more convenient than 24hour PPE. PET-PPE and PETPCl are essentially interchangeable for this purpose, although the former may offer some minor advantages, including simplicity. PPE during baseline PET sustains a strong independent association with later $\mathrm{CV}$ and infectious mortality, and shows a significant association with the risk of peritonitis. These data indicate that PPE should be monitored as a baseline comprehensive marker of outcome in PD patients. 


\section{References}

1. Pollock CA, Cooper BA, Ibels LS, Kantzow E: Nutritional aspects of peritoneal dialysis; in Gokal R, Khanna R, Krediet RT, Nolph KD (eds.): Textbook of Peritoneal Dialysis. Dordrecht, Kluwer Assoc., 2000, pp 515-543.

2. Robey C, Shreedhar K, Batuman V: Effects of chronic peritoneal dialysis on thyroid function tests. Am J Kidney Dis 1989; 13: 99-103.

3. Culleton BF, Wilson PW: Thrombogenic risk factors for cardiovascular disease in dialysis patients. Semin Dial 1999; 12: 117-125.

4. Kim SB, Yang WS, Park JS: Role of hypoalbuminemia in the genesis of cardiovascular disease in dialysis patients. Perit Dial Int 1999; 19(Suppl 2):144-149.

5. Burkart J: Metabolic consequences of peritoneal dialysis. Semin Dial 2004; 17: 498-504.

6. Liu J, Rosner MH: Lipid abnormalities associated with end-stage renal disease. Semin Dial 2006; 19: 32-40.

7. Heimbürger O, Waniewski J, Werynski A, Lindholm B: A quantitative description of solute and fluid transport during peritoneal dialysis. Kidney Int 1992; 41: 1320-1332.

8. Rippe B: A three-pore model of peritoneal transport. Perit Dial Int 1993; 13(Suppl 2):35-38.

9. Buis B, Koomen GCM, Imholz ALT, Struijk DG, Reddingius RE, Arisz L, Krediet RT: Effect of electric charge on the transperitoneal transport of plasma proteins during CPD. Nephrol Dial Transplant 1996; 11: 1113-1120.

10. Devuyst O, Goffin E: Water and solute transport in peritoneal dialysis: models and clinical applications. Nephrol Dial Transplant 2008; 23: 2120-2123.

11. Heaf JG, Sarac S, Afzal S: A high peritoneal large pore fluid flux causes hypoalbuminemia and is a risk factor for death in peritoneal dialysis patients. Nephrol Dial Transplant 2005; 20: 2194-2201.

12. Rippe B, Venturoli D, Simonsen O, de Arteaga J: Fluid and electrolyte transport across the peritoneal membrane during CAPD according to the three-pore model. Perit Dial Int 2004; 24: 10-27.

13. Szeto CC, Chow KM, Lam CWK, Cheung R, Kwan BCH, Chung KY, Leung CB, Li PKT: Peritoneal albumin excretion is a strong predictor of cardiovascular events in peritoneal dialysis patients: a prospective cohort study. Perit Dial Int 2005; 25: 445-452.

14. Sanchez Villanueva R, Bajo A, del Peso G, Fernández Reyes MJ, González E, Romero S, Estrada P, Selgas R: Higher daily peritoneal protein clearance when initiating peritoneal dialysis is independently associated with peripheral artery disease: a possible new marker of systemic endothelial dysfunction? Nephrol Dial Transplant 2009; 24: 1009-1014.

15. Perl J, Huckvale K, Chellar M, John B, Davies SJ: Peritoneal protein clearance and not peritoneal membrane transport status predicts survival in a contemporary cohort of peritoneal dialysis patients. Clin J Am Soc Nephrol 2009; 4: 1201-1206.

16. Twardowski ZJ, Nolph KD, Khanna R, Prowant BF, Ryan LP, Moore HL, Nielsen MP: Peritoneal equilibration test. Perit Dial Int 1987; 7: 138-148.

17. Smit W, Van Dijk P, Langedijk M, Schouten N, Van der Berg N, Struijk D, Krediet R: Peritoneal function and assessment of reference values using a 3.86\% glucose solution. Perit Dial Int 2003; 23: 440-449.

18. Kagan A, Bar-Khayim Y, Schafer Z, Fainaru M: Kinetics of peritoneal protein loss during CAPD: I. Different characteristics for low and high molecular weight proteins. Kidney Int 1990; 37: 971-979.

19. Gomes AM, Pérez Fontán M, Rodríguez-Carmona A, López-Muñiz A, Fernández M, Peteiro J, García-Falcón T: Peritoneal total protein transport assessed from peritoneal equilibration tests with different dialysate glucose concentrations. Perit Dial Int, in press.

20. Haraldsson B: Assessing the peritoneal dialysis capacities of individual patients. Kidney Int 1995; 47: 11871198.

21. Clerbaux G, Francart J, Wallemacq P, Robert A, Goffin E: Evaluation of peritoneal transport properties at onset of peritoneal dialysis and longitudinal follow-up. Nephrol Dial Transplant 2006; 21: 1032-1039.

22. Blake PG, Flowerdew G, Blake RM, Oreopoulos DG: Serum albumin in patients on CAPD - predictions and correlations with outcomes. J Am Soc Nephrol 1993; 3: 1501-1507.

23. Wang T, Heimbürger O, Cheng HH, Bergström J, Lindholm B: Does a high peritoneal transport rate reflect a state of chronic inflammation? Perit Dial Int 1999; 19: 17-22.

24. Kang DH, Yoon KI, Choi KB, Lee R, Lee HY, Han DS, Cho EY, Lee JH: Relationship of peritoneal membrane transport characteristics to the nutritional status in CAPD patients. Nephrol Dial Transplant 1999; 14: 1715-1722.

25. Chung SH, Chu WS, Lee HA, Kim YH, Lee IS, Lindholm B, Lee HB: Peritoneal transport characteristics, comorbid diseases and survival in CAPD patients. Perit Dial Int 2000; 20: 541-547.

26. Margetts PJ, McMullin JP, Rabbat CG, Churchill DN: Peritoneal membrane transport and hypoalbuminemia: cause or effect? Perit Dial Int 2000; 20: 14-18.

27. Cueto-Manzano AM, Correa-Rotter R: Is high peritoneal transport rate an independent risk factor for CAPD mortality? Kidney Int 2000; 57: 314-320.

28. Pecoits-Filho R, Stenvinkel P, Wang AY, Heimbürger O, Lindholm B: Chronic inflammation in peritoneal dialysis: the search for the holy grail?. Perit Dial Int 2004; 24: 327-339.

29. Reyes MJ, Bajo MA, Hevia C, del Peso G, Ros S, de Miguel AG, Cirugeda A, Castro MJ, Sanchez Tomero JA, Selgas R: Inherent high peritoneal transport and ultrafiltration deficiency: their mid-term clinical relevance. Nephrol, Dial Transplant 2007; 22: 218-223.

30. van Biesen W, van der Tol A, Veys N, Dequidt C, Vijt D, Lameire N, Vanholder R: The personal dialysis capacity test is superior to the peritoneal equilibration test to discriminate inflammation as the cause of fast transport status in peritoneal dialysis patients. Clin J Am Soc Nephrol 2006; 1: 269-274. 
31. Kathuria P, Moore HL, Khanna R, Twardowski ZJ, Goel S, Nolph KD: Effect of dialysis modality and membrane transport characteristics on dialysate protein losses of patients on peritoneal dialysis. Perit Dial Int 1997: 17: 449454.

32. Westra WM, Kople JD, Krediet RT, Appell M, Mehrotra R: Dietary protein requirements and dialysate protein losses in chronic peritoneal dialysis patients. Perit Dial Int 2007; 27: 192-195.

33. Pérez Fontán M, Rodríguez-Carmona A, García Naveiro R, Rosales M, Villaverde P, Valdés F: Peritonitis-related mortality in patients undergoing chronic peritoneal dialysis. Perit Dial Int 2005; 25: 274-284.

34. Cooper S, Iliescu EA, Morton AR: The relationship between dialysate protein loss and membrane transport status in peritoneal dialysis patients. Adv Perit Dial 2001; 17: 244-247.

35. Oh KH, Moon JY, Oh J, Kim SG, Hwang YH, Kim S, Lee JS, Ahn C: Baseline peritoneal solute transport rate is not associated with markers of systemic inflammation or comorbidity in incident Korean peritoneal dialysis patients. Nephrol Dial Transplant 2008; 23: 2356-2364. 